\title{
СПЕКТРАЛЬНЫЙ АНАЛИЗ НЕПРИЛИВНЫХ ВАРИАЦИЙ СИЛЫ ТЯЖЕСТИ
}

\author{
Ю. В. Антонов \\ Воронежский государственный университет \\ Поступила в редакцию 21 марта 2019 г.
}

\begin{abstract}
Аннотация: приведены результаты спектрального анализа неприливных вариаций силь тяжести в г. Бишкек (Кыргызстан) в год спокойного Солнца (2018 г.). Предварительно неприливные вариации были разделены на локальную и осредненную части. Анализ проведен отдельно для исходных значений вариаций, локальной и осредненной частей. Все выбросы значений вариаџий за предель средних значений колебаний исключены. Выбросы вариачий связаны преимущественно с землетрясениями. Исключение выбросов показало, что амплитудные спектры практически на протяжении всего года не меняются. Вероятно, остаточные вариачии связаны с собственными колебаниями атмосферы, которые по большей части своей определяются метеорными потоками.

Ключевые слова: лунно-солнечные вариации силь тяжести; неприливные вариации силь тяжести; спектральный анализ; метод осреднения.
\end{abstract}

\section{SPECTRAL ANALYSIS OF NON-TIDAL GRAVITY VARIATIONS}

\begin{abstract}
Bishkek (Kyrgyzstan) in the year of the calm Sun (2018) are presented. Previously non-tidal variations were divided into local and averaged parts. The analysis is carried out separately for the initial values of variations and local and averaged parts. All outliers of variation values beyond the mean values are excluded. Emissions of variations are mainly due to earthquakes. The elimination of emissions showed that the amplitude spectra did not change throughout the year. The residual variations are probably related to the natural fluctuations of the atmosphere, which are mostly determined by meteor showers.
\end{abstract}

Keywords: lunar-solar gravity variations; non-tidal gravity variations; spectral analysis; averaging method.

\section{Введение}

Как показывают исследования [1-6], неприливные вариации силы тяжести во времени определяются лунно-солнечными вариациями, землетрясениями, ударами корональных выбросов масс по магнитосфере и метеорных потоков по атмосфере Земли и т.д. Год 2018 пришелся на год спокойного Солнца, когда воздействие космических факторов на неприливные вариации оказались минимальными. Поскольку влияние космических факторов невелико, то было решено сделать спектральный анализ для всего года. Основной помехой при вычислении спектров служат землетрясения, поэтому от их влияния надо избавляться, о чем будет изложено ниже.

\section{Исходные данные}

Для спектрального анализа использованы мониторинговые наблюдения силы тяжести во времени, выполненные на Бишкекском геодинамическом полигоне РАН (г. Бишкек, Кыргызстан). Измерения силы тяжести проводились гравиметром CG - 5 AUTO-
GRAV, который расположен в в 30 км за городом, так что технические помехи практически исключены. Гравиметр находится в штольне с постоянной температурой (круглый год около $8^{\circ} \mathrm{C}$ ). Прибор позволяет измерять силу тяжести и наклоны по двум ортогональным осям. Одновременно программное обеспечение прибора позволяет вычислять теоретические значения силы тяжести от Луны и Солнца, которые вычитаются из наблюденных значений. Оставшуюся часть измерений, условно назовем неприливной вариацией. Под неприливными вариациями силы тяжести будем понимать все изменения этих полей, исключая лунно-солнечные вариации силы тяжести, вне зависимости от источника их происхождения. Так что неприливная вариация может служить источником для изучения внутреннего строения Земли и космического пространства вокруг Земли.

\section{Методика обработки гравиметрических измерений}

Вычисление неприливных вариаций силы тяжести сейчас конкретно делается следующим образом. На 
первом этапе исключается притяжение Луны и Солнца. В связи с тем, что в программном продукте гравиметра CG - 5 AUTOGRAV, в котором рассчитывается притяжение Луны и Солнца, обнаружены погрешности [2], заново рассчитываются лунно-солнечные вариации силы тяжести и учитываются при обработке. После этого по исправленным значениям определяется линейный тренд, который исключается. Значения тренда в основном отражают сползание нуль-пункта прибора и какую-то низкочастотную часть изменения внешнего гравитационного поля. Оставшуюся часть вариаций после исключения лунно-солнечной части и тренда назовем неприливной вариацией силы тяжести (рис. 1 a). Как показывают исследования $[1,2]$, не-
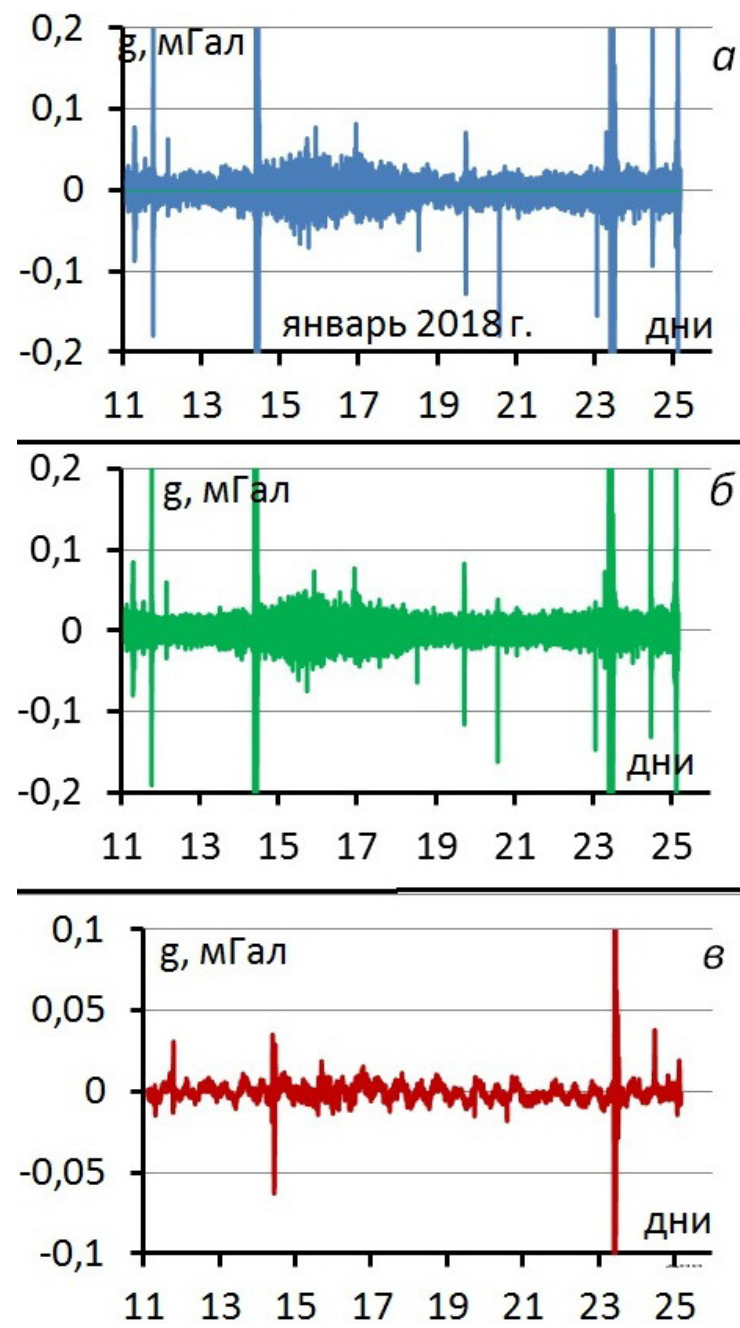

Puc. 1. Разделение неприливной вариации силы тяжести на локальную (остаточную) и осредненную вариации силы тяжести: $a$ - неприливная вариация силы тяжести; $\sigma$ - локальная (остаточная) неприливная вариация ; 6 - осредненная неприливная вариация.

Обсуждение неприливных вариаций силы тяжести

За весь 2018 год была проведена соответствующая обработка наблюденных вариаций силы тяжести и получены неприливная, локальная и осредненная вариации силы тяжести. Неприливные вариации силы приливная вариация с помощью метода осреднения делится на локальную (остаточную) (рис. 1 б) и осредненную (рис. 1 в) неприливные вариации. Кстати, локальная неприливная вариация может быть получена с помощью метода осреднения непосредственно из исходных данных, минуя операции учета лунно-солнечных вариаций силы тяжести и смещения нуль-пункта прибора. Осредненная вариация (рис. 2 a), полученная по исходным наблюдениям, и локальная неприливная вариация силы тяжести (рис. 2 в) практически совпадают между собой. Разность между ними не превышает одного микрогала (рис. 1 б), что минимум на два порядка меньше амплитуды наблюдаемых неприливных вариаций и погрешности измерений.
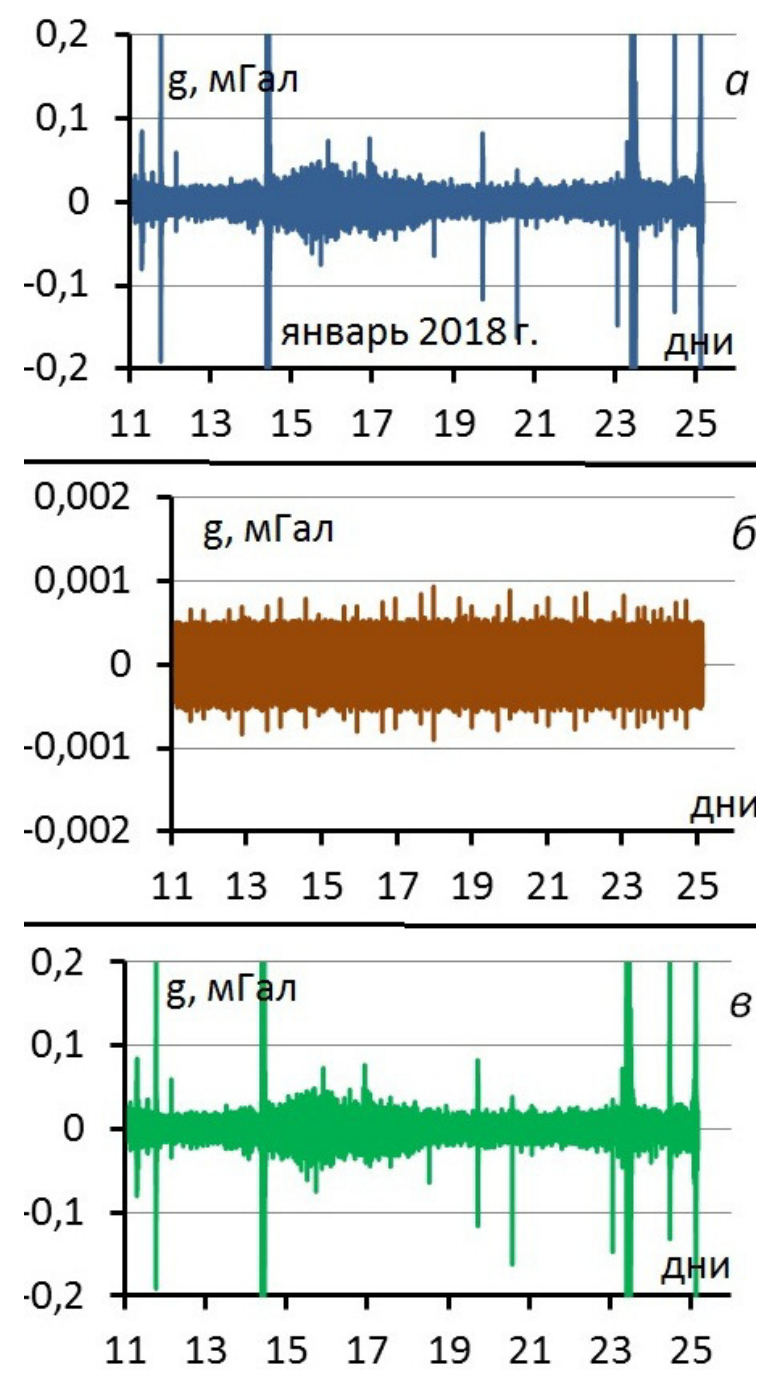

Puc. 2. Сравнение локальных неприливных вариаций полученных с помощью осреднения по исходным наблюдениям вариаций (a), неприливным вариациям силы тяжести (в) и разность между ними (б).

тяжести разбиты примерно на двухнедельные интервалы (около 20000 мин.), что обусловлено хранением информации в гравиметре. Для всех типов полученных аномалий проведен спектральный анализ с помощью программы AutoSignal v1.6. 
Разделение неприливной вариации на остаточные и осредненные составляющие позволяет более четко разделить спектры на высоко - и низкочастотные. Например, на рис. $3 a$ приведена периодограмма для неприливной вариации, представленной на рис. $1 a$. Периодограммы для разделенных вариаций (рис. 16,8 ) существенно отличаются друг от друга. На периодограмме для остаточной неприливной вариации (рис. 1 в) полностью отсутствуют всплески, соответствующие суточному и полусуточному периодам.(1440 и 749 мин)

Для той же периодограммы (рис. $3 a$ ) и ее составными частями (рис. 36, ) наблюдается существенная разница на интервалах 2-100 и 200-2000 мин (рис. 4 a, в). Даже визуально видна разница в периодограммах, особенно для высокочастотной части спектра. Таким образом, разделение неприливных вариаций силы тяжести на локальные составляющие приводит к большей надежности получаемых спектральных характеристик для мониторинговых наблюдений, о чем отмечалось в [2].

Там же [2] отмечалось, что наличие землетрясений в наблюдениях резко искажает спектры неприливных вариаций силы тяжести. Было рекомендовано исключать интервалы с наличием землетрясений. Но при таком подходе теряется часть информации. Предлагается этот вопрос решить с помощью обычного обрезания значений наблюдений в зоне влияния землетрясений. Средняя амплитуда изменения неприливной вариации колеблется в пределах $\pm 0,02-0,05$ мГал, при пульсациях может увеличиваться в два раза. Но пульсации силы тяжести идут с той же частотой, что и неприливные вариации. Длительность пульсации составляет не менее суток. А землетрясения по амплитуде могут быть на два порядка больше амплитуды пульсаций, а по времени продолжаются несколько минут. Поэтому повышенные значения наблюдений за счет землетрясений надо заменить значениями $\pm 0,05$ мГал.
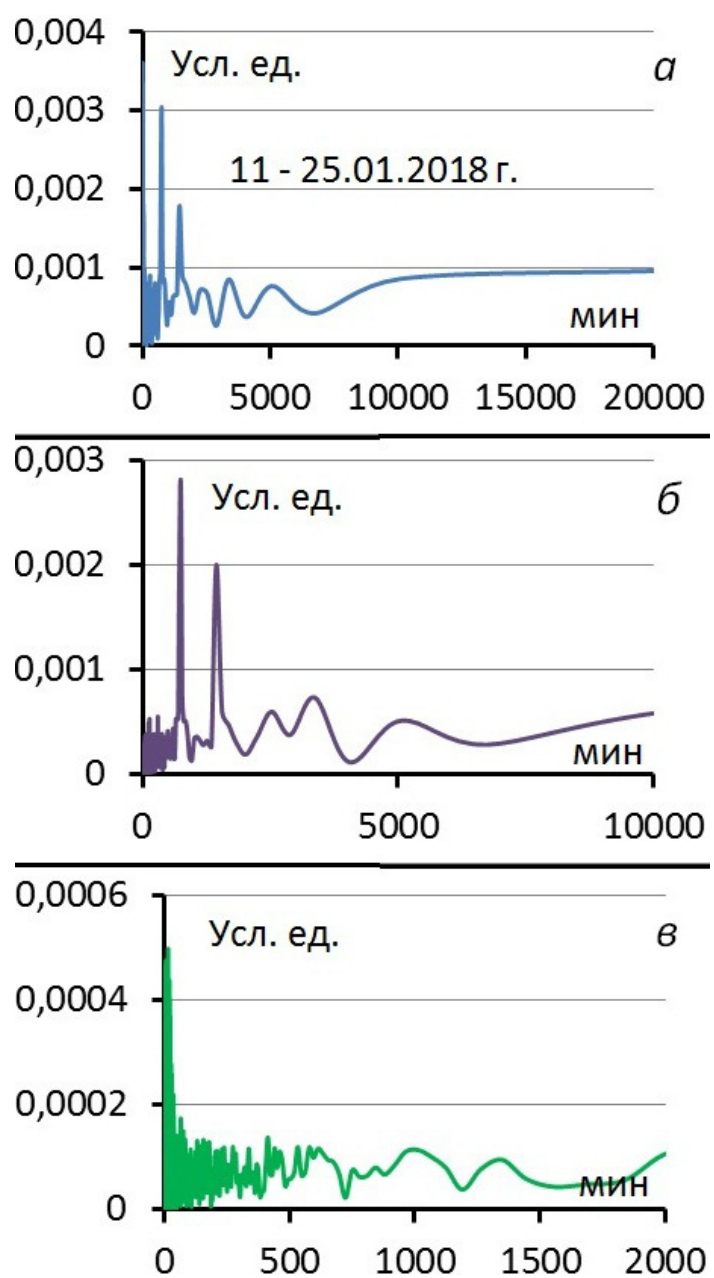

Puc. 3. Сравнение периодограмм неприливной $(a)$, осредненной неприливной (б) и локальной неприливной (в) вариаций силы тяжести.

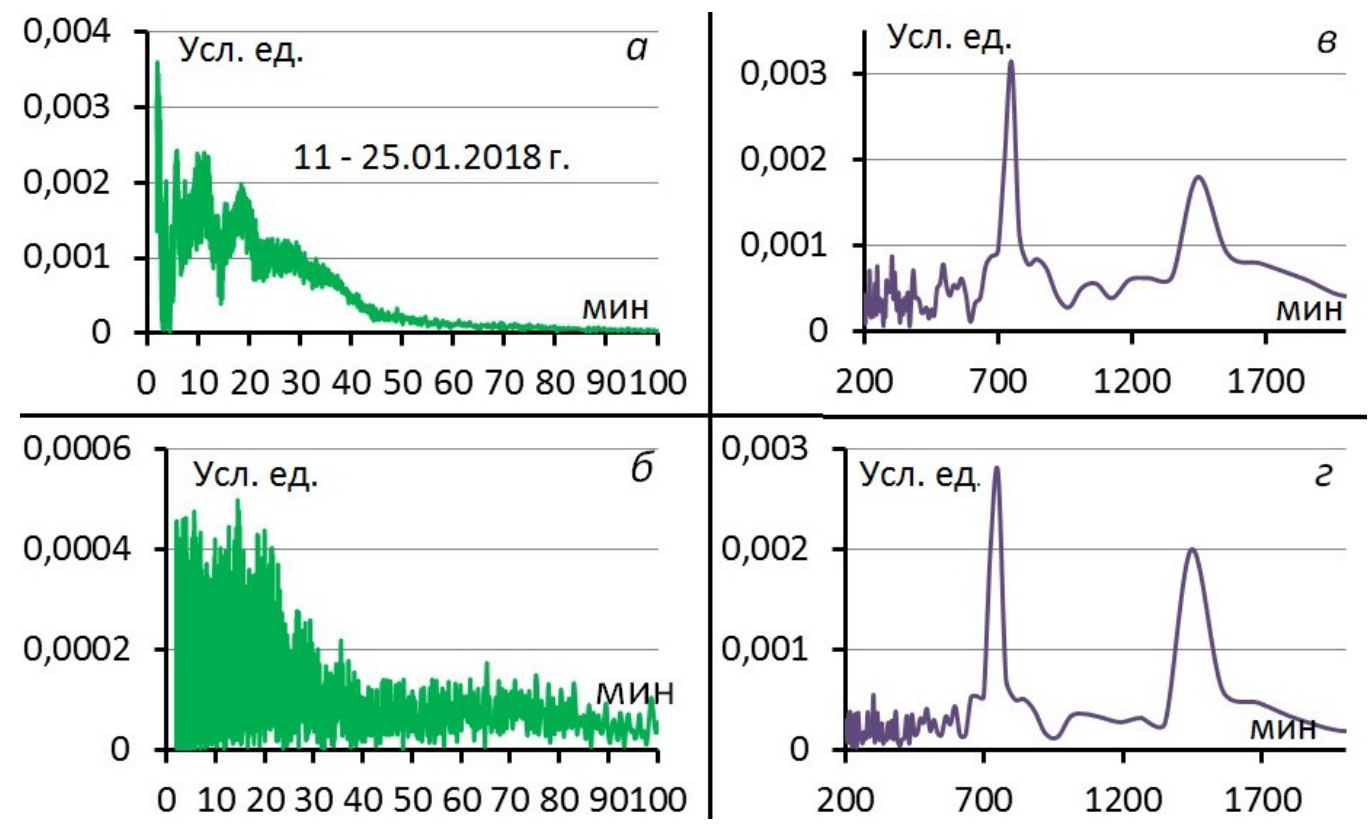

Puc. 4. Сравнение периодограмм исходной неприливной вариации силы тяжести (а, в), локальной (б) и осредненной (г) вариаций в интервале 0 - 100 и $200-2000$ мин. 
Рассмотрим это на практическом материале (рис. $5,6)$. Для примера взяты мониторинговые наблюдения в первой половине мая 2018 г., когда произошла целая серия землетрясений (рис. $5 a$ ). В частности на Гавайях 5 мая магнитуда составила 7 единиц. Но особенно ощутимо было действие землетрясений из-за близости к станции наблюдения 2, 6, 9 и 10 мая в сопредельных регионах (Иран, Афганистан и Таджикистан), где магнитуда составляла от 5,3 до 6,2 единиц. Периодограмма, вычисленная по исходным данным, имеет достаточно невыразительный вид (рис. 5 б). После обрезания числового ряда периодограмма (рис. 5 г) резко поменяла форму. Далее из освобожденной неприливной вариации выделим остаточную вариацию. Периодограмма для остаточной вариации обретает привычную форму (рис. 5 в). То самое можно сказать о периодограммах на интервале 200-2000 мин. (рис. 6). После такой же обработки, например, четко выделился суточный период (рис. 6 2), который первоначально даже не выделялся.

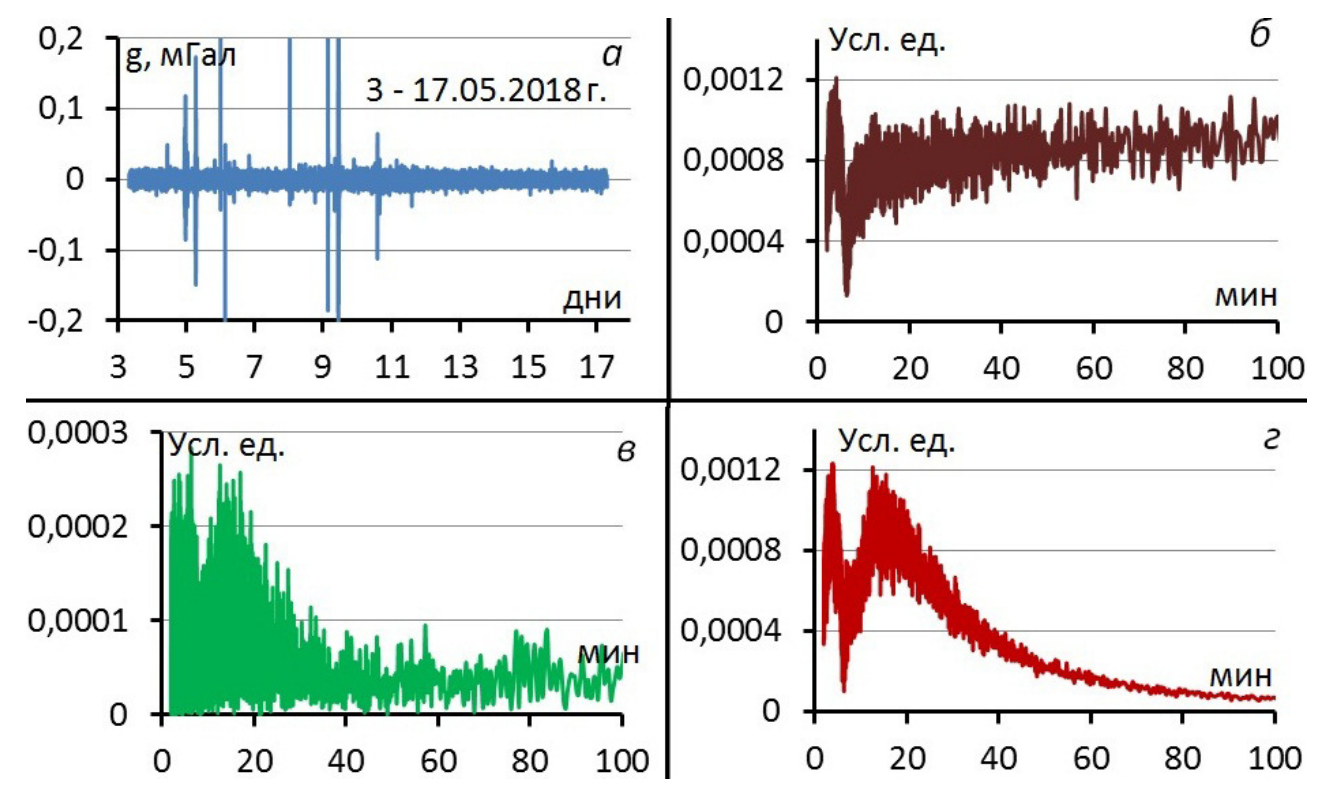

Puc. 5. Влияние землетрясений на спектр неприливных вариаций силы тяжести на интервале 2100 мин. $a-$ неприливная вариация силы тяжести при наличии землетрясения; $\sigma$ - периодограмма неприливной вариация силы тяжести при наличии землетрясения; 8 - периодограмма локальной неприливной вариаций силы тяжести после исключения данных землетрясения; 2 - периодограмма неприливной вариации силы тяжести после разделения.

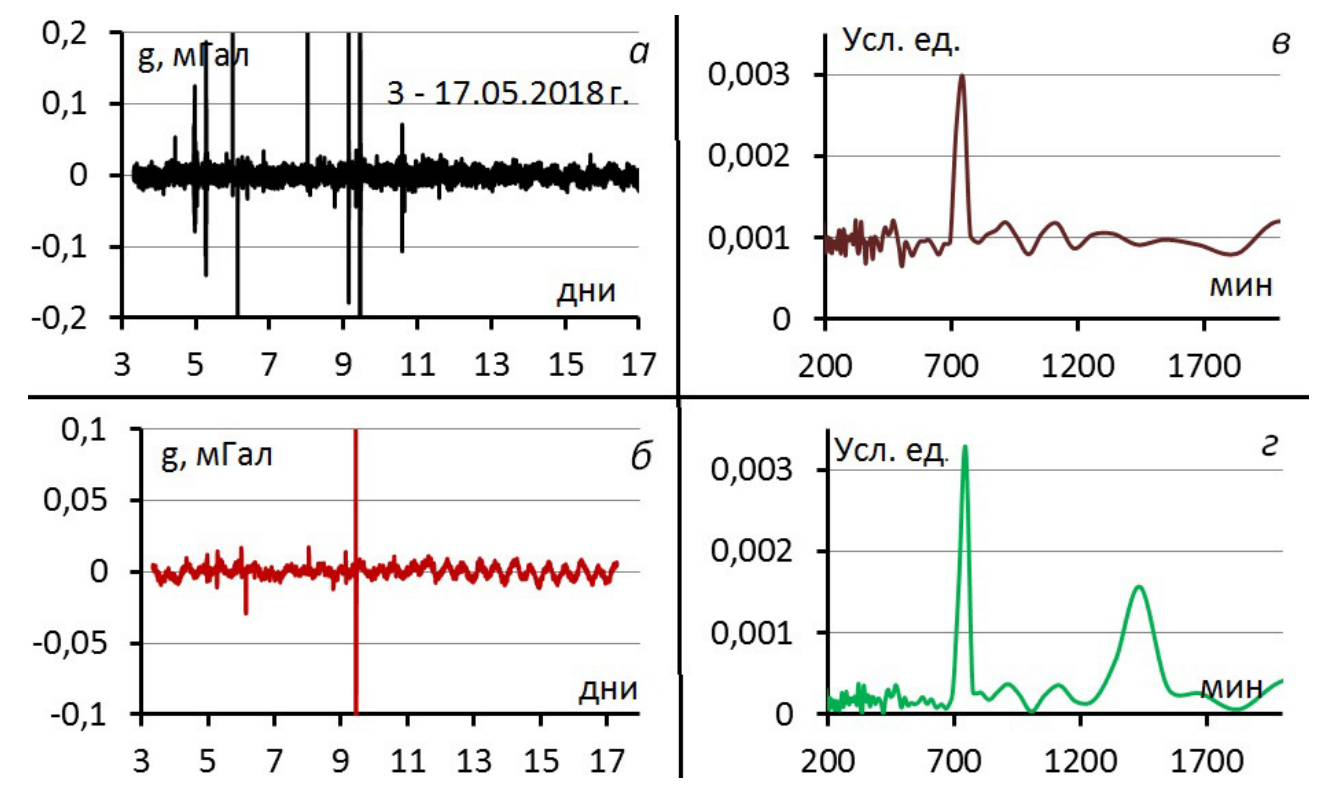

Puc. 6. Влияние землетрясений на спектр неприливных вариаций силы тяжести на интервале 200-2000 мин. $a$ - неприливная вариация силы тяжести при наличии данных о землетрясении; $\sigma$ - осредненная неприливная вариация силы тяжести; 6 - периодограмма локальной неприливной вариаций силы тяжести при наличии данных о землетрясения; 2 - периодограмма осредненной неприливной вариация силы тяжести после исключения данных о землетрясении. 
Наконец, рассмотрим поведение высокочастотной части от сезонности наблюдений. Ранее, не только в [3-6], но и рядом других авторов отмечалась сезонность в сейсмических и гравиметрических наблюдениях. В осенне-зимний период наблюдается повышенная «шумность». Приведенные периодограммы (рис. 7) на все четыре времени года ничем не отличаются друг от друга. Это очень важное обстоятельство и обсудим его ниже. Кроме того в конце приведем данные спектрального анализа за сентябрь 2014 г. (рис. 8, 9). Наблюдения проводились с уменьшением дискретности измерений в три раза (20 сек). Природные помехи практически отсутствовали. Кроме того, в этом месяце была зафиксирована пульсация силы тя- жести (рис. 9 а). Сравнение периодограмм при наличии и без пульсации показывают, что они не отличаются друг от друга. Единственное, что можно отметить - увеличение амплитуды спектра при наличии пульсации.

На всех периодограммах (рис. 3-5) очень четко выделяется максимумы с периодом 12 ч 29 мин. (749 мин.) и 24 ч., на несколько раз превышая остальные максимумы. Природа этих колебаний была предварительно рассмотрена в [2]. На данный момент автор статьи несколько изменил мнение о природе полусуточного и суточного периодов. Период 12 ч 29 мин. с большой вероятностью близок к полусуточной волне M2. Но ведь при вычислении неприливной вариации

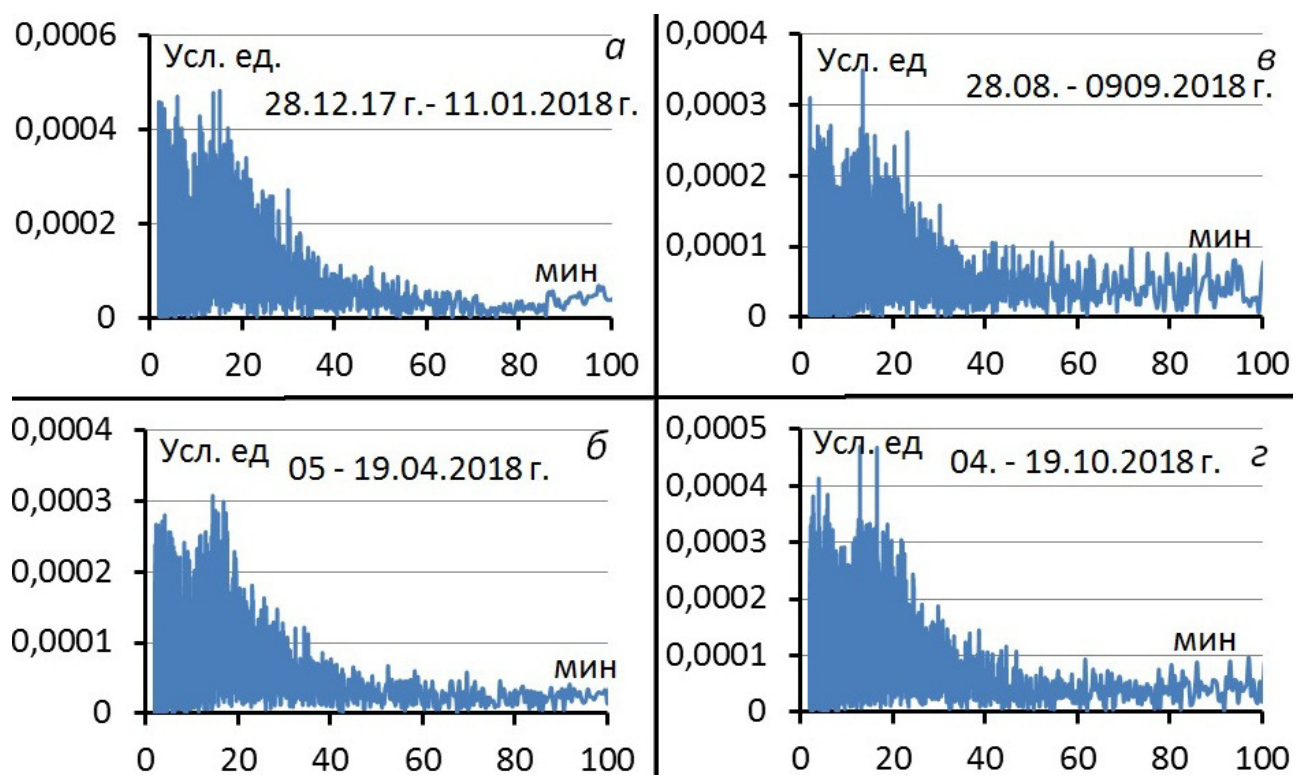

Puc. 7. Сравнение периодограмм остаточных вариаций силы тяжести в разные сезоны года.

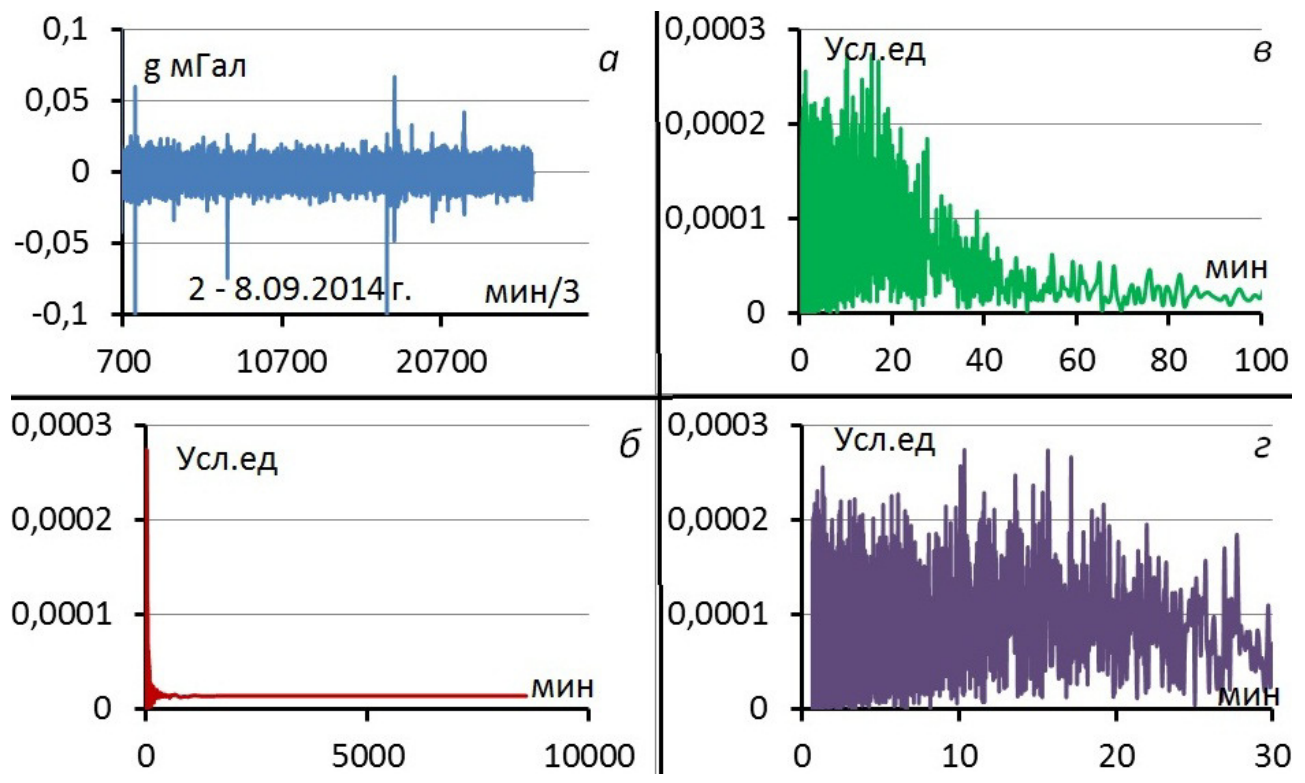

Puc. 8. Периодограммы остаточной вариации силы тяжести при отсутствии пульсаций. $a$ - остаточная вариация силы тяжести; $\sigma$ - спектр остаточной вариации силы тяжести в интервале 0,33-1000 мин; в - спектр остаточной вариации силы тяжести в интервале 0,33-100 мин; 2- спектр остаточной вариации силы тяжести в интервале 0,33-30 мин. 


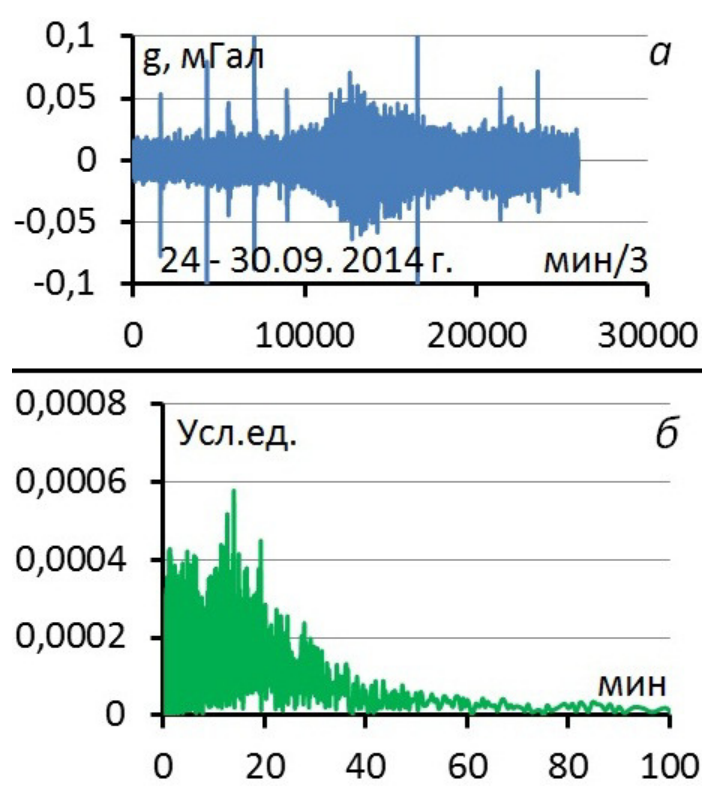

Puc. 9. Периодограммы остаточной вариации силы тяжести при наличии пульсации.

силы тяжести лунно-солнечные вариации были удалены. Следовательно, используемые в программном комплексе гравиметров формулы или не обеспечивают полного учета лунно-солнечных вариаций силы тяжести, или причина кроется в чем-то другом. Делались предположения, что на появление низкочастотных максимумов может в какой-то мере оказывать давление света. Возможно. Но на наш взгляд, предпочтение следует отдать колебаниям атмосферы под действием Солнца. В силу вращения Земли вокруг собственной оси это возмущение в каждой точке земной поверхности периодически меняется со временем. Поскольку оно меняется также в любой точке атмосферы, лунный и солнечный гравитационные приливы существуют и в атмосфере Земли. Но в атмосфере также имеются солнечные тепловые приливы. Первоисточником этих приливов является поглощение солнечного излучения системой атмосфера-поверхность. Не исключено, что дополнительно сюда можно привлечь волны Россби [8].

Переходя к более длинным периодам, можно выделить более слабые максимумы 1082, 1391 и 2020, 2520, 3360, 4040, 5030, 6730 мин. Интересно отметить, что эти периоды связаны между собой отношением полуволна/волна. Это наталкивает на мысль, что периоды имеют одну и ту же физическую природу происхождения. Видимо, свою роль играют не только нутации земной оси, но, в первую очередь, происходящие в атмосфере Земли.

Рассмотрим еще раз спектры (рис. 7) остаточных неприливных вариаций силы тяжести. Все спектры одинаковы в течение 2018 г., и все они лежат в диапа-

ФГБОУ ВО «Воронежский государственный университет» Антонов Юрий Васильевич, доктор технических наук, профессор кафедры геофизики

E-mail: yuriyantonov@yandex.ru; Tел.: +7(473) 2208385 зоне 2-20 мин. А такие периоды определяются внутренними гравитационными волнами в атмосфере $[8$, 10]. Возникают они (волны) в результате изменения плотности воздуха с высотой и перепада давления и температур. Казалось бы, притяжение атмосферы по сравнению с притяжением Земли ничтожно мало $(0,87$ мГал), но в атмосфере под действием внешних факторов $[6,7,9,10]$ могут возникать изменения силы тяжести до 0,02-0,05 мГал, что вызывает в атмосфере колебания, приводящие затем к непредвиденным изменениям погоды.

\section{Заключение}

Таким образом, по результатам спектрального анализа можно уверенно сказать, что неприливные вариации силы тяжести определяются не только воздействием внешних космических сил и геодинамическими процессами, протекающими внутри Земли, но и атмосферой Земли. Атмосфера окружает Землю, поэтому влияние всех внешних и внутренних факторов находит отклик в атмосфере, тем самым определяя состояние как самой атмосферы, так и состояние геофизических полей внутри и вне нее.

\section{ЛИТЕРАТУРА}

1. Антонов, Ю. В. Пульсации неприливных вариаций силы тяжести / Ю. В. Антонов // Изв. ВУЗов. Геол. и разведка. 2014. - № 5. - C. 54-57.

2. Антонов, Ю. В. Разделение неприливных вариаций силы тяжести на основе спектрального анализа и метода осреднения/ Ю. В. Антонов // Вестник Воронеж. гос. ун-та. Сер.: Геология. - 2016. - № 2. - С. 100-106.

3. Антонов, Ю. В. Синхронные пульсации в неприливных вариациях гравитационного и сейсмического полей / Ю. В. Антонов, И. А. Сизаск // Геология и разведка. Изв. ВУЗ. 2015. - №5. - C. 46-52.

4. Антонов, Ю.В. Сравнение приливных вариаций силы тяжести и вертикальной составляющей сейсмографа / Ю. В. Антонов, И. Ю. Антонова // Геофизика. - 2013. - № 2. - С. 27-31.

5 Антонов, Ю. В. Влияние атмосферного фронта на показания гравиметров и сейсмометров / Ю. В. Антонов // Геология и разведка. Изв. ВУЗ. - 2017. - №4. - С. 66-71.

6. Антонов, Ю. В. Всплески неприливных вариаций силы тяжести / Ю. В. Антонов // Геофизика. - 2017. - №1. - С. 28-34.

7. Бычков, С. Г. Вычисление аномалий силы тяжести при высокоточных гравиметрических съемках / С. Г. Бычков, А. С. Долгаль, А. А. Симанов. - Пермь: УрО РАН, 2015. - 142 с. 8. Дикий, Л. А. Теория колебаний земной атмосферы / Л. А. Дикий. - Л.: Гидрометеоиздат, 1969. - 195 с.

9. Howard, T. A. Stealth Coronal Mass Ejections: A Perspective / T. A. Howard, R. A. Harrison // Solar Physics. - 2013. - V. 285. - P. 269-280.

10. Boy, J.-P. Global atmospheric loading and gravity / J.-P. Boy, J. Hinderer, P. Gegout // Phys. Earth Planet. Inter. - 1998. - V. 109. - P. 161-177.

\section{Voronezh State University}

Antonov Y. V., Doctor of Engineering Sciences, professor Geophysical Department

E-mail: yuriyantonov@yandex.ru; Tel.:+7 (472) 2208385 